San Antonio Review • San Antonio Review (Issue 2 | Winter 2019)

\title{
Que No Puedo Entregar
}

Brittany Leitner

Published on: Aug 11, 2019

Updated on: Aug 30, 2020

License: Creative Commons Attribution 4.0 International License (CC-BY 4.0). 


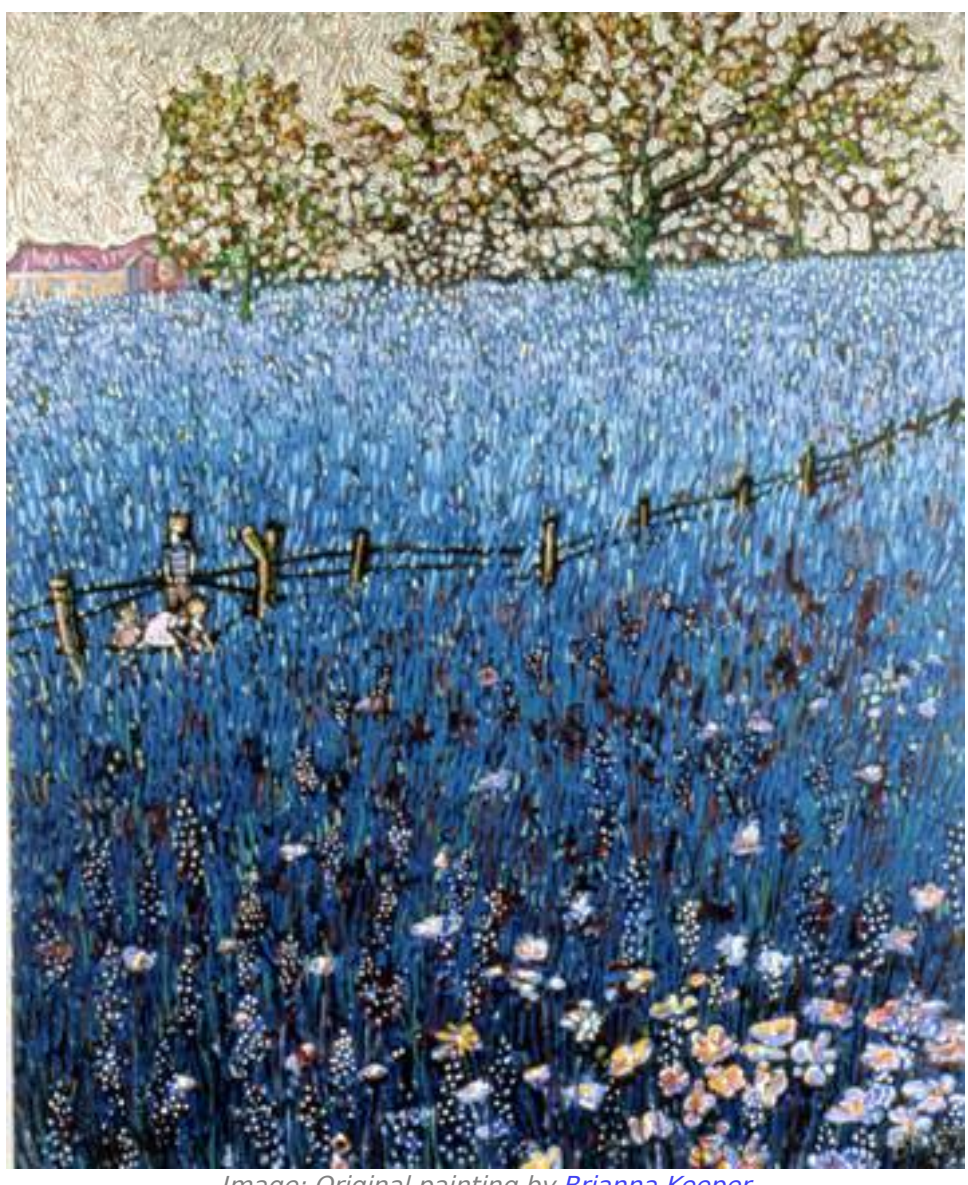

Image: Original painting by Brianna Keeper

after i finally write about being mexican i am told i can't write a whole book about being mexican

$\mathrm{i}$ tell my boyfriend he is white privilege and he smiles because $\mathrm{i}$ have it too $\mathrm{i}$

don't know what i have when no one is looking but $i$ think of my mom and she is the mexican one i know el chico del apartamento cinco doce but it's not because my mom told me about him it's my sister she 
sings to him near the stereo

and $i$ wonder if he sits on the

stoop like me and has big plans

to tell the world he's not

mexican or if he'll always be trapped

in that song que no puedo entregar $\mathrm{i}$

sit and try to untangle my

blood but my veins snap like

accordion pulls and they come

back to form the mariachi band

that lives on my shoulder and

sings to me when i can not dream

Brittany Leitner is a journalist and poet living in New York City and originally from San Antonio, Texas. Her articles and poems have been published in Bustle, Elite Daily, No Dear, Palette Poetry, The Write Launch and elsewhere. Poems from her 2018 chapbook 23 Emotions have won the Sequestrum new writer award, the International Merit Award from the Atlanta Review and third place in the 2018 Palette Poetry Prize judged by Shane McCrae. 